\title{
Pelatihan Microsoft Excel Sebagai Penunjang Ketrampilan Hard Skill Bagi Siswa Pada SMK YPSEI Palangka Raya
}

\author{
San Petro ${ }^{1}$ \\ STIE YBPK Palangka Raya, sanpetro@stieybpk.ac.id \\ Karnadi Handoko Swatan ${ }^{2}$ \\ STIE YBPK Palangka Raya, karnadiwatan18@gmail.com
}

\begin{abstract}
Abstrak
Pada era Revolusi Industri 4.0, peran mata pelajaran TIK (Teknologi Informasi dan Komunikasi) sangat dibutuhkan bagi para siswa sebagai bekal bagi mereka dalam menghadapi perubahan dan tuntutan jaman. Sejak adanya penerapan kurikulum 2013 (K-13), TIK hanya diajarkan pada Sekolah Menengah Kejuruan untuk lintas minat atau pendalaman minat bidang teknologi informasi dan komunikasi saja, tidak diwajibkan secara umum. SMK berperan sebagai sekolah yang menyelenggarakan pendidikan kejuruan yang menerapkan program keahlian seperti teknik mesin, perkantoran, seni rupa, tata boga, administrasi dll yang dapat memberi bekal salah satunya ketrampilan hard skill yang menunjang profesional skill. Mengoperasikan komputer merupakan bagian ketrampilan hard skill, siswa perlu memiliki ketrampilan dalam mengoperasikan program yang terdapat di Windows dan program yang paling sering digunakan yaitu Microsoft Excel. Microsoft Excel umumnya dikenal sebagai software pengolah angka atau bisa dikatakan sebagai program aplikasi lembar yang berfungsi mengolah data secara otomatis seperti perhitungan, rumus, pemakaian fungsi, tabel, pembuatan grafik dan manajemen data untuk menciptakan data informasi digunakan dalam rangka pengambilan keputusan. Pemanfaatan sarana lab komputer yang belum dilaksanakan secara maksimal digunakan siswa karena tidak adanya mata pelajaran yang berkaitan secara langsung dengan komputer sehingga pemanfaatan program komputer seperti Microsoft Excel belum maksimal diterapkan di sekolah-sekolah. Dengan adanya kegiatan pelatihan terkait Microsoft Excel yang dilaksanakan di SMK YPSEI, diharapkan siswa dapat memiliki bekal ketrampilan penggunaan aplikasi komputer sebagai sarana TIK secara praktik. Tujuan dari kegiatan ini adalah memberikan edukasi bagi siswa tentang program komputer Microsoft Excel. Metode pelatihan menggunakan metode tutorial disertai adanya pre test dan post test. Hasil dari pelatihan menunjukan pada hari pertama, dari jumlah 23 peserta Kelas X nilai pre test semua peserta berada dibawah skor 50, sedangkan pada saat post test ada 4 peserta mengalami peningkatan nilainya diatas skor 50. Pada hari kedua, dari jumlah 19 peserta kelas XI nilai pre test hanya 1 peserta nilainya diatas skor 50, sedangkan pada saat post test ada 11 peserta mengalami peningkatan nilainya mencapai skor 50 keatas. Pemahaman awal para peserta kelas X dan kelas XI terhadap Microsoft Excel sebelum diadakan pelatihan ini masih rendah, dan selama pelatihan menunjukan adanya peningkatan pemahaman dan ketrampilan dari beberapa peserta dalam mengoperasikan Microsoft Excel.
\end{abstract}

Kata Kunci: Microsoft Excel, Ketrampilan Hard Skill, Siswa 
Jurnal Pengabdian Kepada Masyarakat

\begin{abstract}
In the era of the Industrial Revolution 4.0, the role of ICT (Information and Communication Technology) subjects was very much needed for students as a provision for them to face the changes and demands of the times. Since the implementation of the 2013 curriculum (K-13), ICT is only taught at Vocational High Schools for cross-interest or deepening of interest in the information and communication technology field, not generally required. Vocational School acts as a school that organizes vocational education that implements expertise programs such as mechanical engineering, offices, fine arts, catering, administration, etc. which can provide provisions, one of which is hard skills that support professional skills. Operating a computer is part of the hard skills, students need to have skills in operating the programs found in Windows and the program most often used is Microsoft Excel. Microsoft Excel is generally known as a number processing software or it can be said as a sheet application program that functions to process data automatically such as calculations, formulas, use of functions, tables, graphs and data management to create information data used in the context of decision making. Utilization of computer lab facilities that have not been maximally used by students because there are no subjects directly related to computers so that the use of computer programs such as Microsoft Excel has not been maximally applied in schools. With the existence of training activities related to Microsoft Excel which is carried out at SMK YPSEI, it is hoped that students will have the skills to use computer applications as ICT facilities in practice. The purpose of this activity is to provide education for students about Microsoft Excel computer programs. The training method uses the tutorial method accompanied by pre-test and post-test. The results of the training showed that on the first day, out of the 23 participants in Class X, the pre-test scores of all participants were below the score of 50, while at the time of the post-test there were 4 participants who experienced an increase in value above the score of 50. On the second day, out of the 19 class XI participants pre-test only 1 participant the value above the score of 50, while at the time of the post-test there were 11 participants experienced an increase in value reaching a score of 50 and above. The initial understanding of the participants of class $X$ and class XI of Microsoft Excel prior to the training was still low, and during the training, there was an increase in understanding and skills of some participants in operating Microsoft Excel.
\end{abstract}

Keywords: Microsoft Excel, Hard Skill Skills, Students

\title{
Pendahuluan
}

\section{Latar Belakang}

Pada era Revolusi Industri 4.0, peran mata pelajaran TIK (Teknologi Informasi dan Komunikasi) sangat dibutuhkan bagi para siswa sebagai bekal bagi mereka dalam menghadapi perubahan dan tuntutan jaman. Namun, hal ini kurang didukung oleh perkembangan sistem kurikulum SMA/MA di Indonesia (Bona, 2018). Sejak adanya penerapan kurikulum 2013 (K-13), bidang TIK menjadi seperti anak tiri. TIK itupun hanya diajarkan pada SMK untuk lintas minat atau pendalaman minat bidang teknologi informasi dan komunikasi saja, tidak diwajibkan secara umum.

SMK sebagai sekolah yang menyelenggarakan pendidikan kejuruan yang menerapkan program keahlian seperti teknik mesin, perkantoran, seni rupa, tata boga, administrasi dll mempunyai peran penting memberi bekal salah satunya hard skill yang menunjang profesional skill seperti memahami penggunaan komputer. Hard skill merupakan ketrampilan teknis dalam bidang ilmu pengetahuan dan teknologi yang diperoleh dari otodidak, bangku sekolah, kuliah, pelatihan (Thunder, 2018). Siswa 
perlu memahami program yang terdapat di Windows, program yang paling sering digunakan di Windows adalah produk dari Microsoft yaitu Microsoft Office.

Pada era digitalisasi kreatifitas anak menjadi sangat penting, karena itu perlu pembekalan program komputasi seperti Microsoft Office salah satunya Microsoft Excel. Microsoft Excel diberbagai kebutuhan sering digunakan seperti menyusun laporan keuangan (Fajrinshanty, Herawati, \& Atmadja, 2019), pelatihan dalam pengelolaan data dan penyusunan laporan keuangan (Mulyani, Wibisono, Alawiyah, \& Warnilah, 2019) (Arsi, Pambudi, \& Maisa, 2019), penerapan ilmu statistik di SMA seperti penginputan data ke tabel (Sihombing \& Rahmawati, 2019), pelatihan atau traning oleh lembaga kursus (Hutahaean, Azhar, Siagian, Syah, \& Informasi, 2019), masih banyak hal lain yang bisa dilakukan microsoft excel. Microsoft Excel merupakan program aplikasi lembar kerja yang termasuk dalam bagian Microsoft Office seperti Word, Power Point, Access pada umumnya. Fungsi program excel untuk mengolah data secara otomatis seperti perhitungan, rumus, pemakaian fungsi, tabel, pembuatan grafik dan manajemen data (Abdullah, Millenia, Nusfiana, Ariance, \& Krisnawati, 2019). Microsoft Excel adalah program aplikasi pengolah angka yang dikeluarkan oleh Microsoft Corporation (Sumberpengertian.id, 2017).

Sesuai dalam bidang sarana dan prasarana yang berkategori standar nasional, sekolah biasanya memfasilitasi siswa salah satunya dengan ketersediaan Lab Komputer (Murman, 2017). Kendatipun demikian, ada sekolah-sekolah tertentu karena keterbatasan dana dan keterbatasan lahan tidak menyediakan fasilitas tersebut. Pemanfaatan sarana lab komputer yang terjadi biasanya dilakukan secara terbatas digunakan siswa untuk ujian masuk ke sekolah, UN, dan kegiatan penunjang lainnya. Ada atau tidak mata pelajaran yang berkaitan secara langsung dengan komputer hanya berkaitan dengan kegiatan multi media saja, sehingga pemanfaatan program komputer seperti Microsoft Office belum maksimal diterapkan di sekolah.

\section{Tujuan}

Berangkat dari permasalahan tersebut, perlu adanya edukasi tentang aplikasi komputer yaitu pengenalan program komputer Microsoft Office seperti Microsoft Excel dan memanfaatkan sebagai sarana pembelajaran siswa. Dengan adanya kegiatan pelatihan terkait Micrsoft Excel ini diharapkan siswa dapat memiliki bekal ketrampilan penggunaan aplikasi komputer yang memadai digunakan sebagai sarana TIK secara praktik.

\section{Manfaat}

Kegiatan PKM ini diharapkan siswa-siswi SMK YPSEI Palangka Raya dapat ketrampilan mengoperasikan aplikasi komputer dengan baik dan untuk mengetahui seberapa jauh kemampuan para siswa dalam mengoperasikan Microsoft Excel sehingga akan memberikan manfaat bagi mereka sebagai bekal dalam kesiapan mereka ketika masuk dunia kerja maupun perguruan tinggi yang membutuhkan ketrampilan dalam aplikasi komputer.

\section{Metode}

Kegiatan pelatihan dilaksanakan di SMK YPSEI Palangka Raya, sekolah ini menekankan pada bidang adminitrasi perkantoran. SMK YPSEI sudah memiliki 
ketersediaan sarana lab komputer, LCD Proyektor, jumlah komputer 20 unit ditambah 5 laptop. Siswa yang diambil sebagai sampel adalah 25 siswa dari kelas $x$ (sebagai pilot test) pada hari pertama dan 25 siswa dari kelas xi pada hari kedua.

Langkah-langkah Kegiatan meliputi:

Perencanaan. Agar program ini berjalan secara maksimal maka diperlukan perencanaan secara tepat, diantaranya: 1) Menentukan aplikasi Microsoft Excel (memilih menggunakan Microsoft Excel 2010); 2) Membuat ppt atau power point untuk presentasi dan menyusun materi handout untuk dibagikan dikelas; 3) Meminta 1 (satu) mahasiswa dari kampus STIE YBPK menjadi asisten dalam kegiatan ini; 4) Mengunjungi sekolah yang dipilih dalam kegiatan ini yaitu SMK YPSEI dan bertemu Kepala Sekolah untuk meminta ijin mengadakan kegiatan PKM disana; 5) Mengecek fasilitas lab komputer sekolah dan berkoordinasi dengan kepala lab; 6) Menyesuaikan waktu pelaksanaan kegiatan selama 2 hari berdasarkan kordinasi dengan pihak sekolah; 7) Mempersiapkan sarana dan prasarana kegiatan (fotokopi, konsumsi dll).

Pelaksanaan. Pelaksanaan kegiatan dibagi menjadi 3 yaitu:

1. Metode pelaksanaan hari pertama yang dilakukan: 1) Pembacaan doa; 2) Melaksanakan kegiatan Pre Test; 3) Mempresentasikan microsoft excel, diselingi pembahasan soal dan peserta mempraktikkan microsoft excel di komputer (tutorial); 5) Istirahat; 6) Melaksanakan Post Test; 7) Memberikan konsumsi. Metode pelaksanaan hari kedua yang dilakukan: 1) Pembacaan doa; 2) Melaksanakan kegiatan Pre Test; 3) Melakukan pembahasan terkait tes; 4) Mempresentasikan microsoft excel dan peserta mempraktikkan microsoft excel di komputer (tutorial); 5) Istirahat; 6) Melaksanakan Post Test; 7) Memberikan konsumsi.

2. Sarana prasarana dan peralatan yang diperlukan: Ruang laboratorium komputer sekolah; LCD; Komputer / Laptop; Handout.

3. Teknik pelaksanaan: Pelaksanaan kegiatan Pengabdian Kepada Masyarakat (PKM) ini dilakukan dengan menggunakan metode tutorial dan memberikan tes (pre dan post) untuk mengetahui pemahaman siswa tentang Microsoft Excel secara bertahap. Adapun sistematika pelaksanaan kegiatan sebagai berikut: 1) Siswa terlebih dahulu melaksanakan pre test untuk mengetahui seberapa besar pemahaman mereka sebelumnya tentang microsoft excel. 2) Siswa diarahkan penyaji secara tutorial dan memahami bacaan yang di handout. 3) Siswa mulai diarahkan untuk mengerjakan latihan yang ada didalam handout, peserta diberikan kesempatan untuk bertanya apabila ada kesulitan dalam mengoperasikan Microsoft Excel sehingga perlu dibantu. Setelah selesai tugas disimpan pada folder yang telah ditentukan. 4) Siswa melaksanakan post test untuk mengetahui pemahaman mereka setelah mengikuti kegiatan pelatihan berlangsung.

\section{Hasil dan Pembahasan}

Dari hasil pre test kelas $\mathrm{x}$ nilai dari para siswa yang memperlihatkan bahwa nilai berada dibawah atau < score 50, sedangkan hasil nilai pre test kelas xi hanya satu orang yang mencapai angka diatas $>$ score 50 . Hal ini menunjukan bahwa sebelum pelatihan 
ini diselenggarakan, pengetahuan terkait Microsoft Excel masih sangat minim dan para siswa banyak yang belum pernah mengoperasikan Microsoft Excel. Tidak adanya ketrampilan siswa sebagai penunjang profesional skill dalam mempelajari dan mengoperasikan komputer maupun aplikasinya akan menyebabkan ketertinggalan dan lemahnya kreatifitas dalam bidang TIK.

Dari hasil post test kelas $\mathrm{x}$ menunjukan bahwa prosentase tingkat kenaikan nilai mencapai $69,5 \%$ dari jumlah siswa kelas $\mathrm{x}$ yang mengikuti tes, meskipun demikian kenaikan kurang signifikan karena hanya 4 siswa yang nilainya diatas score 50 . Hal ini dikarenakan pertama, kelas $x$ hanya digunakan sebagai pilot test untuk kelas xi. Kedua, pembahasan terkait jawaban untuk pre test tidak semua dibahas karena bersamaan dengan presentasi dari penyaji dan keterbatasan waktu. Ketiga, siswa banyak yang tidak membaca handout. Sedangkan dari kelas xi hasil post test menunjukan bahwa prosentase tingkat kenaikan nilai mencapai 52,63\% dari jumlah siswa kelas xi yang mengikuti tes, hal ini dikarenakan pembahasan jawaban pre test dibahas secara keseluruhan sebelum penyaji masuk dalam materi yang dipresentasikan dan banyak diantara mereka menyempatkan diri untuk membaca handout pada penyajian materi dan saat beristirahat, sehingga ada 11 siswa yang nilainya diatas atau sama dengan score 50. Kelas X dan Kelas XI menunjukan adanya peningkatan dari yang belum memahami menjadi memahami pengoperasian Microsof Excel. Lihat pada gambar 1 dan gambar 2 dibawah ini:

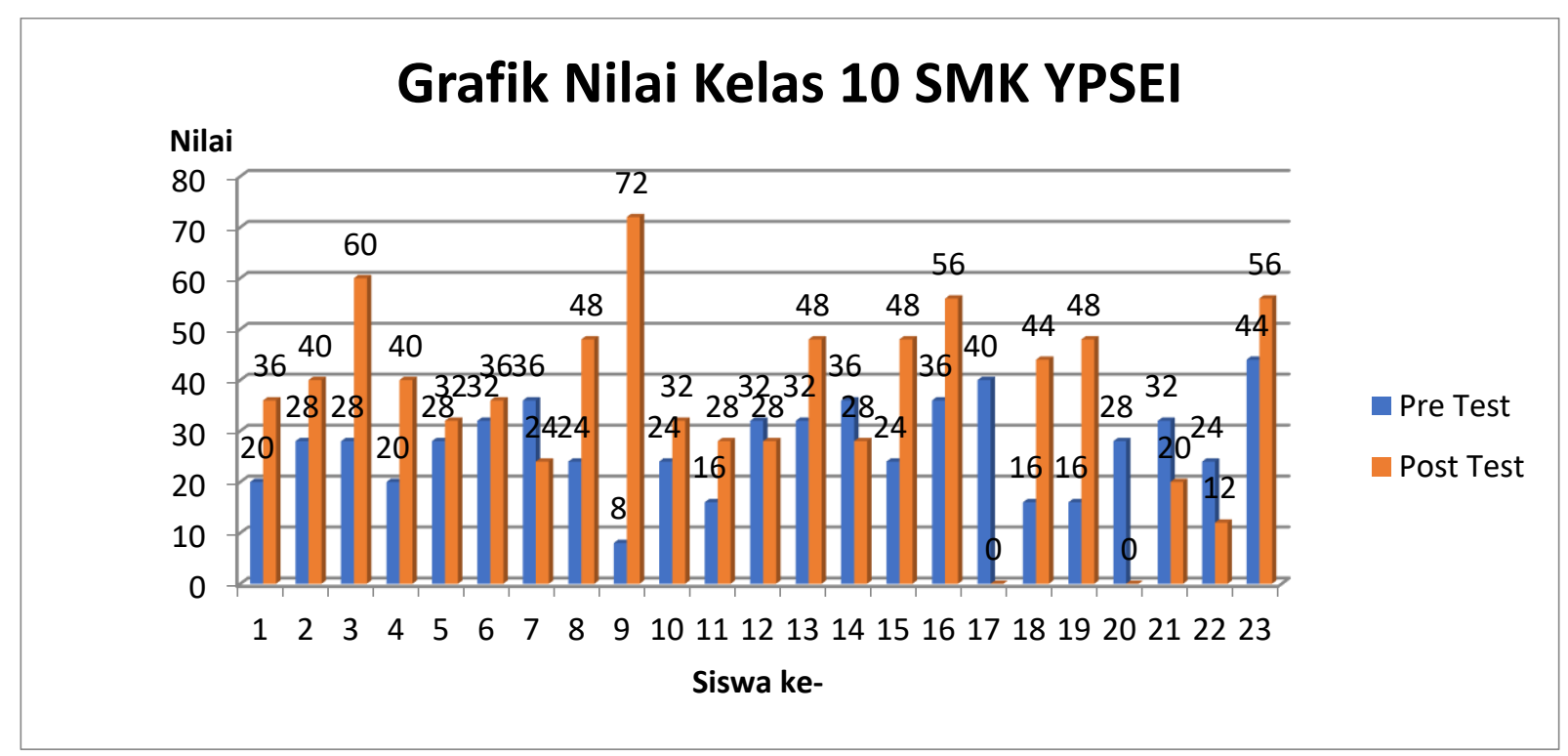

Gambar 1 Grafik Nilai Kelas X untuk Pre Test dan Post Test 


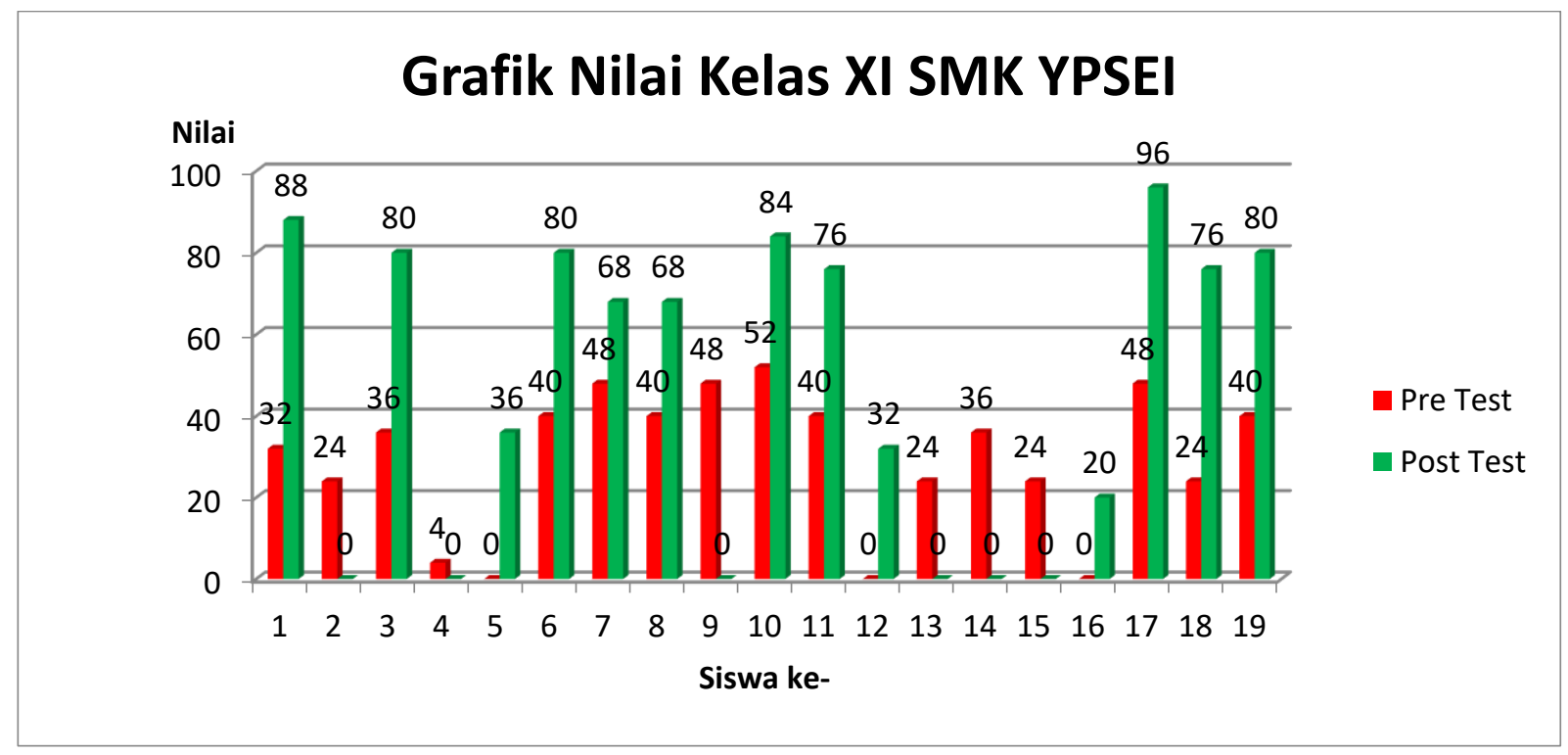

Gambar 2 Grafik Nilai Kelas XI untuk Pre Test dan Post Test

Jumlah peserta yang dipilih berdasarkan quota sampling berjumlah 25 siswa kelas $\mathrm{x}$ dan dan 25 siswa kelas xi, hal ini disesuaikan dengan jumlah unit komputer yang ada di lab komputer sekolah. Dari 25 siswa kelas $x$ yang diundang pada hari pertama ternyata yang mengikuti hanya berjumlah 23 peserta, sedangkan dari 25 siswa kelas xi yang diundang pada hari kedua ternyata yang mengikuti kegiatan hanya 19 peserta. Karena awal kegiatan tahun ajaran baru 2019 dan PPDB menyebabkan belum aktifnya kegiatan belajar mengajar, sehingga banyak siswa yang tidak datang ke sekolah. Dari 23 peserta yang mengikuti pada hari pertama, sebanyak 2 orang siswa yang tidak mengikuti post test. Sedangkan pada hari kedua, dari 16 siswa yang hadir bertambah 3 siswa yang hadir terlambat hanya mengikuti post test, sehingga menjadi 19 peserta, sebanyak 6 orang siswa tidak mengikuti post test.

\section{Simpulan dan Rekomendasi}

Pemahaman awal para peserta kelas X dan kelas XI terhadap Microsoft Excel sebelum diadakan pelatihan ini masih rendah, dan selama pelatihan menunjukan adanya peningkatan pemahaman dan ketrampilan dari beberapa peserta dalam mengoperasikan Microsoft Excel. Saran yang diberikan sebaiknya kegiatan pelatihan komputer seperti Microsoft Excel perlu ditingkatkan, perlunya kesadaran dari siswa, para guru selaku pihak sekolah terkait, pemerintah daerah agar melek terhadap mata pelajaran TIK menghindari ketertinggalan dan miskin kreatifitas di era digitalisasi. SMK YPSEI maupun setiap sekolah menengah yang telah mempunyai sarana lab komputer yang memadai sebaiknya memberikan tambahan ekstrakulikuler pelajaran aplikasi komputer sebagai program minat belajar.

\section{Daftar Pustaka}

Abdullah, D., Millenia, D., Nusfiana, D., Ariance, E., \& Krisnawati, F. (2019).

Persamaan dan Perbedaan Microsoft Excel. INA-Rxiv, 2016-2018.

Arsi, P., Pambudi, A. S., \& Maisa, W. (2019). Peningkatan Kualitas SDM dengan 
Pemanfaatan Iptek Melalui Pelatihan Komputer Dasar dan Internet Pada Anggota Polsek Kedungbanteng. Jurnal Abdimas BSI, 2(2), 191-196. Retrieved from

https://ejournal.bsi.ac.id/ejurnal/index.php/abdimas/article/view/4244/3281 Bona, F. M. (2018). Sempat Dihapus, TIK Kembali Diajarkan pada 2019. Retrieved July 23, 2019, from www.beritasatu.com website: https://www.beritasatu.com/nasional/508445/sempat-dihapus-tik-kembalidiajarkan-pada-2019

Fajrinshanty, I., Herawati, N. T., \& Atmadja, A. T. (2019). PENERAPAN STANDAR AKUNTASI KEUANGAN ENTITAS TANPA AKUNTABILITAS PUBLIK (SAK ETAP) PADA UD SINAR ABADI. JIMAT (Jurnal Ilmiah Mahasiswa Akuntansi) Undiksha, 8(2).

Hutahaean, J., Azhar, Z., Siagian, Y., Syah, A. Z., \& Informasi, S. (2019). Pelatihan pembuatan blog pada siswa lembaga kursus pendidikan (lkp) mandiri. 2(1), 65-74.

Mulyani, Y. S., Wibisono, T., Alawiyah, T., \& Warnilah, A. I. (2019). Pelatihan Komputer Dasar Untuk Mendukung Proses Kegiatan Belajar Mengajar ( KBM) Bagi Guru-Guru RA / TPQ / DTA Al-Ishlaah Kota Tasikmalaya. Jurnal Abdimas BSI, 2(2), 234-240. Retrieved from https://ejournal.bsi.ac.id/ejurnal/index.php/abdimas/article/view/5768/pdf Murman, L. (2017). Permasalahan Sekolah dan Solusinya (2): Pemenuhan Sarana Prasarana. Retrieved July 23, 2019, from Gurusiana website: http:/ / murman.gurusiana.id/article/ permasalahan-sekolah-dan-solusinya-2pemenuhan-sarana-prasarana-4488414

Sihombing, S. C., \& Rahmawati. (2019). Penyuluhan Penerapan Ilmu Statistik di SMAN 1. 3(1), 47-52.

Sumberpengertian.id. (2017). Pengertian Microsoft Excel, Fungsi dan Kegunaannya (LENGKAP !). Retrieved July 23, 2019, from Sumberpengertian.id website: http://www.sumberpengertian.id/pengertian-microsoft-excel Thunder, J. (2018). Pentingnya "Hardskill" dan "Softskill" dalam Dunia Karir. Retrieved July 23, 2019, from www.kompasiana.com website: https://www.kompasiana.com/jonithunder/5bf23690ab12ae448c353bb4/penti ngnya-hardskill-dan-softskill-dalam-dunia-karir\# 